\title{
ESTROGENIC AND ANTIESTROGENIC ACTIVITIES OF COMMERCIAL DIETARY SUPPLEMENTS CONTAINING HERBAL INGREDIENTS AND ISOFLAVONES
}

\author{
PARAMITA BASU, SHARON SUNNY, CAMELIA MAIER*
}

Department of Biology, Texas Woman's University, Denton, TX 76204-5799, USA

Email: cmaier@twu.edu

Received: 13 Aug 2016 Revised and Accepted: 21 Sep 2016

\begin{abstract}
Objective: This study aimed to assess the estrogenic and antiestrogenic activities of five dietary supplements, commercially available for treatment of menopausal symptoms, before and after gastrointestinal digestion by employing a yeast steroid-regulated transcription system.

Methods: Supplements (S) were extracted with either 80\% methanol or water. Water extracts were subjected to simulated gastrointestinal (GI) digestion. Estrogenic and antiestrogenic activities were assessed by a steroid-regulated transcription system in Saccharomyces cerevisiae expressing the human estrogen receptor alpha.

Results: The highest estrogenic activities were detected in both S1 methanol (2342.5 \pm 20.83 MU) and water (1225.6 \pm 20.6 MU) extracts (400 estradiol equivalents). Extracts showed antiestrogenic properties by reducing the transcriptional activity induced by estradiol in transgenic yeast. The highest antiestrogenic activity was detected in S2 methanol extract and S3 water extract, which inhibited estradiol activity by $76 \%$ and $64 \%$, respectively. After GI digestion, S1, S2 and S3 extracts showed significantly higher estrogenic and antiestrogenic activities as 'serum-available' than 'colon-available' samples and S4 and S5 extracts showed significantly higher activities as 'colon-available' than 'serum-available' samples.

Conclusion: All dietary supplements revealed estrogenic and antiestrogenic activities. The GI digestion demonstrated the availability of phytoestrogens for absorption in the blood stream. Supplements containing soy isoflavones and alfalfa ingredients had the highest estrogenic activities and could be more effective than supplements with complex plant formulation in alleviating menopausal symptoms and treating osteoporosis. The transgenic yeast assays proved to be a powerful tool for assessing the in vitro estrogenic and antiestrogenic activities of dietary
\end{abstract} supplements.

Keywords: Antiestrogenic, Dietary supplement, Estrogenic, Phytoestrogens, Simulated gastrointestinal digestion

(c) 2016 The Authors. Published by Innovare Academic Sciences Pvt Ltd. This is an open access article under the CC BY license (http://creativecommons.org/licenses/by/4. 0/) DOI: http://dx.doi.org/10.22159/ijpps.2016v8i11.14687

\section{INTRODUCTION}

Estrogen hormones are important for the development of sexual characteristics, reproduction, and overall health, especially for women's health, as estrogens are the primary hormones responsible for a majority of functional pathways in reproduction, cardiovascular, neuronal and skeletal systems [1]. Women between the ages of 40-60 are affected by changes in estrogen levels that result in the onset of menopause. Menopausal women suffer from a variety of symptoms, such as hot flashes, night sweats, mood swings, insomnia, vaginal dryness, in addition to long-term complications such as osteoporosis [2]. This period of transition is often eased by undergoing hormone replacement therapy (HRT) or taking specially formulated dietary supplements containing phytoestrogens. In either case, the objective of the treatment is to replenish estrogenic levels to alleviate menopausal symptoms and prevent osteoporosis. In 2002, the Women's Health Initiative (WHI) publicized the increased risk of developing breast cancer due to the hormone replacement therapy [3], which has led to a rise in alternative and complementary therapies for menopause, most of which include botanical supplements $[4,5]$.

Plants are known to produce estrogen-like compounds or phytoestrogens, which are non-steroidal polyphenolic compounds structurally similar to the mammalian estrogen $17 \beta$-estradiol. Phytoestrogens, which are present in dietary supplements that are widely marketed as natural alternatives to hormone replacement therapy, function similarly to animal estrogens in that they bind to estrogen receptors (ER) inducing transcription of target genes in human cells [6]. The chemical structures and functions of phytoestrogens and their effects in mammals have been studied extensively since their discovery in the 1920 s $[7,8]$. More recently, the publicized increased risk of developing breast cancer due to the hormone replacement therapy $[3,9]$, also led to a rise in development and use of supplements containing phytoestrogens for use in alleviating menopausal symptoms. However, not enough studies on the effectiveness of supplements in replenishing the estrogen levels needed to lessen the menopausal symptoms have been published so far.

Phytoestrogens also are found to be inhibitors of estrogen-mediated tumorigenesis [10]. Besides treating/preventing the menopausal symptoms and osteoporosis, botanical supplements containing isoflavone phytoestrogens are known to be associated with decreased postmenopausal breast cancer risk [8]. The abovementioned study reported that women consuming isoflavonecontaining supplements had a reduced risk for breast cancer in Ontario, Canada [11]. Clinical studies are also supported by in vitro studies indicating that isoflavones, mainly genistein, exhibited antiestrogenic activities at higher concentrations $(>20 \mu \mathrm{M})$ and thus inhibited the proliferation of breast cancer cells $[12,13]$.

Given the significant interest in the dietary supplements aimed at alleviating menopausal symptoms, the present study was undertaken to assess the estrogenic and antiestrogenic activities of five commercial dietary supplements before and after simulated GI digestion, in an effort to evaluate the bioavailability of phytoestrogens in the supplement formulations. To the best of our knowledge, this is the first study reporting the estrogenic and antiestrogenic activities of dietary supplements before and after GI digestion by employing an estrogen-regulated transcription system.

\section{MATERIALS AND METHODS}

Chemicals

Ortho-Nitrophenyl- $\beta$-galactoside (ONPG), $17 \beta$-estradiol, sodium phosphate dibasic heptahydrate $\left(\mathrm{Na}_{2} \mathrm{HPO}_{4} \cdot 7 \mathrm{H}_{2} \mathrm{O}\right)$, sodium phosphate 
monobasic, monohydrate $\left(\mathrm{NaH}_{2} \mathrm{PO}_{4} \cdot \mathrm{H}_{2} \mathrm{O}\right)$, potassium chloride $(\mathrm{KCl})$, magnesium sulfate $\left(\mathrm{MgSO}_{4} \cdot 7 \mathrm{H}_{2} \mathrm{O}\right)$, D-(+)-glucose, 2-Mercaptoethanol $\left(\mathrm{C}_{2} \mathrm{H}_{6} \mathrm{OS}\right)$ and 200-proof ethyl alcohol $\left(\mathrm{CH}_{3} \mathrm{CH}_{2} \mathrm{OH}\right)$ were purchased from Sigma-Aldrich (St. Louis, MO, USA). Yeast nitrogen base (YNB) was from United States Biological (Salem, MA, USA). Cassamino acids were from BD Difco (San Jose, CA, USA). Adenine sulfate $\left(\mathrm{C}_{5} \mathrm{H}_{5} \mathrm{~N}_{5} \mathrm{O}_{5} \mathrm{H}_{2} \mathrm{SO}_{4}\right.$ ) was from Acros Organics (NJ, USA). Dietary supplements were purchased from two suppliers in Denton, Texas, USA.

\section{Preparation of dietary supplement extracts}

Dietary supplements were extracted in $80 \%$ methanol or water as the daily dosage recommended by the manufacturers (table 1) at room temperature for $2 \mathrm{~d}$ and then centrifuged at 3,000-4,000 rpm for $20 \mathrm{~min}$. All supernatants were filtered through Whatman \# 54 filter paper, and water extracts were filter sterilized. The filtrates were centrifuged at $10,000 \mathrm{rpm}, 4^{\circ} \mathrm{C}$ for $15 \mathrm{~min}$ and stored at- $20^{\circ} \mathrm{C}$ for further study.

Table 1: Recommended dose and composition of dietary supplements containing herbal ingredients and isoflavones

\begin{tabular}{lll}
\hline Supplement & $\begin{array}{l}\text { Recommende } \\
\text { d dose/day }\end{array}$ & Content \\
\hline S1 Alfalfa & 3 tablets & Organic Alfalfa (Medicago sativa, Fabaceae) leaf, 1800 mg \\
S2 Solaray®'s Black & 4 tablets & Black Cohosh (Cimicifuga racemosa, Ranunculaceae) root, $540 \mathrm{mg}$
\end{tabular}

S3 Estro Pause Menopause 4 liquid softSupport gels

Calcium as calcium carbonate and calcium citrate, $500 \mathrm{mg}$; Magnesium as magnesium oxide and magnesium citrate, $200 \mathrm{mg}$; Fish oil, $2158 \mathrm{mg}$; John's Wort (Hypericum perforatum, Hypericaceae) extract, $300 \mathrm{mg}$; Soy isoflavones, $100 \mathrm{mg}$; Black cohosh extract, $80 \mathrm{mg}$; Red clover (Trifolium pretense, Fabaceae) powder, $40 \mathrm{mg}$; Asian Ginseng (Panax ginseng, Araliaceae) extract, $31 \mathrm{mg}$; Chaste Tree (Vitex agnus-castus, Lamiaceae) fruit extract, $20 \mathrm{mg}$

S4 Advanced Therapeutics 2 tablets Soy isoflavone concentrate, $125 \mathrm{mg}$; Genistin, $25 \mathrm{mg}$; Daidzin, $19.25 \mathrm{mg}$; Glycitin, $5.75 \mathrm{mg}$

Isoflavone Rx-

Phytoestrogen ${ }^{\circledR}$

S5 Meno Care for

Menopausal Comfort ${ }^{\circledR}$

4 capsules

Herbal blend ( $800 \mathrm{mg}$ ) containing: Asoka tree (Saraca asoca, Fabaceae) bark; Shatavari (Asparagus racemosus, Asparagaceae) root; Chebulic Myrobalan (Terminalia chebula, Combretaceae) fruit rind; Heart-leaf Sida (Sida cordifolia, Malvaceae) root; Licorice (Glycyrrhiza glabra, Fabaceae) root; Gotu Kota (Centella asiatica, Apiaceae) whole plant

\section{Simulated gastrointestinal (GI) digestion}

Simulated GI digestion of supplement water extracts was performed by the method of McDougall et al. [14] (fig. 1). Each supplement extract $(2.5 \mathrm{ml})$ was added to the $17.5 \mathrm{ml}$ simulated stomach solution (1.6 g pepsin, $1 \mathrm{~g} \mathrm{NaCl}, \mathrm{pH} 2)$. The mixture was incubated at $37{ }^{\circ} \mathrm{C}$ and $100 \mathrm{rpm}$ in a shaking water bath for $2 \mathrm{~h}$ (Gastric Phase, fig. 1). The intestinal phase of the simulated GI was assembled as follows: the gastric phase solution was placed in a glass beaker along with $4.5 \mathrm{ml}$ of a mixture of $4 \mathrm{mg} / \mathrm{ml}$ pancreatin, and $25 \mathrm{mg} / \mathrm{ml}$ bile salts and a segment of cellulose dialysis tubing (molecular weight cut off $12 \mathrm{kDa}$ ) containing $1 \mathrm{M} \mathrm{NaHCO}_{3}$ to neutralize the titratable acidity was placed in the gastric phase solution and the beaker was incubated at $37^{\circ} \mathrm{C}$ for $2 \mathrm{~h}$. At the end of the incubation period, the solution in the beaker constituted the 'OUT SAMPLE,' representing material that remains in the gastrointestinal tract (colon-available) and the solution that diffused into the dialysis tubing constituted the 'IN SAMPLE,' representing the serum available material. All samples were centrifuged at $16,000 \mathrm{rpm}$, filtered through $0.45 \mu \mathrm{m}$ nylon syringe filters and stored at $-20^{\circ} \mathrm{C}$ for further analyses.

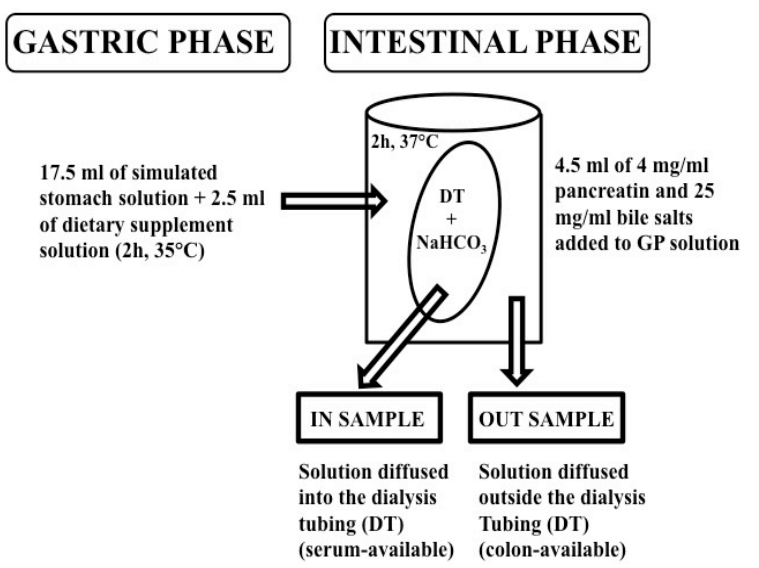

Fig. 1: Schematic representation of simulated GI digestion. GP, gastric phase; DT, dialysis tubing

\section{Estrogenic and antiestrogenic assays}

The estrogenic and antiestrogenic assays were performed according to the method of Maier et al. [15]. In short, estrogen (E) equivalents in each non-digested and digested dietary supplement extracts were estimated based on a $17 \beta$-estradiol standard curve. A steroidregulated Saccharomyces cerevisiae system [BJ3505 (MAT a, pep4::His 3, prbl-D1.6R, his3-D200, lys2-801, trpl-D101 (gal3), ura352(gal2), can1)] was used to determine the estrogenic and antiestrogenic activities of extracts. Yeast cells contained the expression plasmid YEPE10 expressing the human ER $\alpha$ and YRPE2, a reporter plasmid expressing the $E$. coli $\beta$-galactosidase enzyme (lacZ) gene. Yeast cultures were grown in a cassamino acid-glucose medium (CAA medium-20\% glucose, $10 \%$ yeast nitrogen base, and $5 \%$ adenine sulfate) at $230 \mathrm{rpm}, 30{ }^{\circ} \mathrm{C}$, overnight in an incubatorshaker. For the estrogenic assays, cultures were inoculated with 100 $\mu \mathrm{g}, 200 \mu \mathrm{g}, 300 \mu \mathrm{g}$, or $400 \mu \mathrm{g} \mathrm{E}$ equivalents of non-digested or digested dietary supplements extracts. Cultures inoculated with $2 \mu \mathrm{g}$ estradiol or with $2 \mu \mathrm{g}$ genistein were used as positive controls and yeast cultures without any treatments were used as negative controls for all experiments. Average estradiol activity was 2,500 $\mathrm{MU}$, and average genistein activity was $900 \mathrm{MU}$. For antiestrogenic assays, cultures were inoculated with $100 \mu \mathrm{g}, 200 \mu \mathrm{g}, 300 \mu \mathrm{g}$, or 400 $\mu \mathrm{g} E$ equivalents of non-digested or digested supplement extracts and $2 \mu \mathrm{g}$ of estradiol. The antiestrogenic activity of extracts translates in a reduction of the transcriptional activity induced by estradiol in transgenic yeast, as active compounds in extracts compete with $\mathrm{E}$ for the ligand-binding site of the ER. All cultures were allowed to grow in the incubator-shaker for six hours. After six hours, the cells were disrupted with glass beads, the protein concentrations in supernatants were estimated, estrogenic and antiestrogenic assays were performed as previously described [15]. Estrogenic activity was calculated according to the formula:

$\mathrm{MU}=\{0$. D. at $420 \mathrm{~nm}\} /\{$ Protein concentration (g) $\mathrm{x}$ Time (min) $\} \mathrm{x}$ 1000 and expressed in Miller Units (MU).

Antiestrogenic activity was expressed as percentage using the formula:

(Activity of supplement+estradiol)/(Activity of estradiol) x 100

\section{Statistical analysis}

Means and standard deviations (SD) of three experiments were calculated. One-way ANOVA was performed, and significance of differences among means was determined by Tukey's test $\left({ }^{*} \mathrm{P} \leq 0.05\right)$. 


\section{RESULTS AND DISCUSSION}

Both non-digested methanol and water supplement extracts showed increased estrogenic and antiestrogenic activities with increasing concentrations (table 2). The highest estrogenic activities were detected in S1 methanol $(2342.6 \pm 20.8 \mathrm{MU})$ and water $(1225.6 \pm 20.6 \mathrm{MU})$ extracts ( $400 \mathrm{E}$ equivalents). The estrogenic activities of other methanol extracts of non-digested dietary supplements ranked as follows: S3 and S4>S2 and $\mathrm{S} 5$ and of water extracts: $\mathrm{S} 3>\mathrm{S} 2>\mathrm{S} 4>\mathrm{S} 5$ (table 2).
Supplement extracts showed antiestrogenic properties by reducing the transcriptional activity induced by estradiol in transgenic yeast. The highest antiestrogenic activities were detected in S2 methanol extract and in S1 and S3 water extracts, which inhibited estradiol activity by $76 \%$ and $60 \%$ and $64 \%$, respectively (table 2 ).

The antiestrogenic activities of other methanol extracts at $400 \mathrm{E}$ equivalents ranked as follows: S3 and S4>S1 and S5 and of water extracts: S5>S2 and S4 (table 2).

Table 2: Estrogenic and antiestrogenic activities of non-digested dietary supplement extracts

\begin{tabular}{|c|c|c|c|c|}
\hline \multicolumn{5}{|l|}{ Estrogenic activities (MU) } \\
\hline 80\% Methanol Extracts & 100E Equiv & 200E Equiv & 300E Equiv & 400E Equiv \\
\hline S1 & $188.9 \pm 8^{(\mathrm{a})(*)}$ & $1101.8 \pm 20.6$ & $1453.3 \pm 3.4$ & $2342.6 \pm 20.8$ \\
\hline S2 & $13.3 \pm 3.3$ & $86.1 \pm 9.5^{(b)}$ & $221.1 \pm 16^{(\mathrm{b})}$ & $273.3 \pm 1.1^{(\mathrm{b})}$ \\
\hline S3 & $214.4 \pm 15^{(*)}$ & $353.9 \pm 27.2$ & $944.2 \pm 30$ & $1653.6 \pm 26^{(\mathrm{c})}$ \\
\hline S4 & $402 \pm 3.1$ & $567 \pm 20$ & $720 \pm 17.2$ & $1620.8 \pm 11^{(\mathrm{c})}$ \\
\hline S5 & $152.2 \pm 2.2^{\text {(a) }}$ & $175.6 \pm 13.3^{(\mathrm{b})}$ & $239.4 \pm 4^{(b)}$ & $361.7 \pm 7.3^{(\mathrm{b})}$ \\
\hline \multicolumn{5}{|l|}{ Water Extracts } \\
\hline S1 & $282 \pm 9(\mathrm{a})\left(^{*}\right)$ & $308.3 \pm 3.9^{(a)}$ & $311.7 \pm 2^{(*)}$ & $1225.6 \pm 20.6$ \\
\hline S2 & $\left.353.3 \pm 6.7^{*}\right)$ & $376.7 \pm 8.9^{(b)}$ & $638.1 \pm 19$ (b) & $829.5 \pm 20$ \\
\hline S3 & $273.9 \pm 17(\mathrm{ac})$ & $310 \pm 2.2^{(* a)}$ & $594.5 \pm 23^{(b)}$ & $960.8 \pm 12$ \\
\hline S4 & $241 \pm 0.3^{(\mathrm{ac})}$ & $366.1 \pm 10.6^{(b)}$ & $401.2 \pm 3^{(*)}$ & $443.9 \pm 6.1$ \\
\hline S5 & $157.2 \pm 1.7$ & $208.6 \pm 0.8$ & $213.3 \pm 6^{(*)}$ & $281.1 \pm 6.7$ \\
\hline \multicolumn{5}{|c|}{ Antiestrogenic activities (\%) } \\
\hline $80 \%$ Methanol Extracts & 100E Equiv & 200E Equiv & 300E Equiv & 400E Equiv \\
\hline S1 & $14.5 \pm 1.4^{(*)}$ & $30.5 \pm 2.3^{(\mathrm{a})(*)}$ & $42.2 \pm 2.2^{(\mathrm{a})}$ & $52.7 \pm 1.9(\mathrm{a})\left({ }^{*}\right)$ \\
\hline S2 & $4.8 \pm 1.4^{(\mathrm{b})}$ & $35.5 \pm 4.6^{(\mathrm{ab})}$ & $49.1 \pm 2^{(b)}$ & $76.4 \pm 3.3^{(*)}$ \\
\hline S3 & $26.5 \pm 0.2^{(*)}$ & $35.2 \pm 0.3^{(a b c)}$ & $39.3 \pm 1^{(a b c)}$ & $62.7 \pm 4.9(\mathrm{c})$ \\
\hline S4 & $8.3 \pm 0.6^{(b)}$ & $18.3 \pm 0.8^{(*)}$ & $40 \pm 0.3^{(\mathrm{abcd})}$ & $62.1 \pm 0.4^{(c)}$ \\
\hline S5 & $4.1 \pm 0.6^{(\mathrm{b})}$ & $28.6 \pm 1^{(\mathrm{abc})\left({ }^{*}\right)}$ & $44 \pm 0.2^{(\mathrm{abcd})}$ & $54.8 \pm 3^{(a)}\left({ }^{*}\right)$ \\
\hline \multicolumn{5}{|l|}{ Water Extracts } \\
\hline S1 & $9.4 \pm 3.5^{(\mathrm{a})\left(^{*}\right)}$ & $27.1 \pm 1.8^{(\mathrm{a})}$ & $28.9 \pm 4(a)(*)$ & $60.2 \pm 9.2^{(a)(*)}$ \\
\hline S2 & $18.2 \pm 1^{(b)(*)}$ & $29.5 \pm 2^{(\mathrm{a})(*)}$ & $32 \pm 8^{(a b)(*)}$ & $39.9 \pm 7(b)\left({ }^{*}\right)$ \\
\hline S3 & $4.6 \pm 0.1^{(a b c)}$ & $20 \pm 0.3^{(\mathrm{ac})\left({ }^{*}\right)}$ & $32 \pm 0.3^{(a b c)}$ & $64.2 \pm 1^{(a)(*)}$ \\
\hline S4 & $21 \pm 1^{(\mathrm{bcd})\left(^{*}\right)}$ & $20.9 \pm 3.3^{(\mathrm{acd})}$ & $30 \pm 1^{(a b c d)\left({ }^{*}\right)}$ & $37.4 \pm 4^{(b)}\left({ }^{*}\right)$ \\
\hline S5 & $14.3 \pm 1^{(\mathrm{abcd})}$ & $20.3 \pm 1.1^{\text {(acd) }}$ & $30 \pm 5.2^{\text {(abcd) }}$ & $46.9 \pm 1$ \\
\hline
\end{tabular}

Results represent means \pm SD of three independent experiments (each experiment had two replicates; $n=6$ ). In each column, mean values with no superscript letters are significantly different from each other at $\mathrm{E} 0.01$; mean values with * are significantly different fro $\mathrm{m}$ each other at $\mathrm{P} \leq 0.05$; mean values with same superscript letters are not significantly different (Tukey's test).

The high estrogenic activity of S1 dietary supplement extracts (table 2) was induced by the phytoestrogens in its active ingredient, alfalfa (table 1). This plant is known to contain coumestrol, apigenin, luteolin, quercetin and other chemicals that exhibit estrogenic activity $(16,17]$. A study employing Italian women showed that use of alfalfa extracts for three months completely alleviated hot flashes and night sweating in 20 out of 30 women [18]. The Health, Eating, Activity, and Lifestyle (HEAL) study showed that 31 alfalfa users had a substantially lower risk of hot flashes demonstrating the effect of alfalfa in alleviating the menopausal symptoms [19].

The S2 dietary supplement contains black cohosh root as an active ingredient (table 1). Although S2 methanol extract showed low estrogenic activity, the water extract had a significantly higher estrogenic activity (table 2). The root and rhizome of black cohosh have been researched for over $30 \mathrm{y}$ for the relief of menopauserelated symptoms and have been shown to be effective for the treatment of menopausal symptoms such as hot flushes, profuse sweating, sleeping disorders and nervous irritability [20]. Thus, The North American Menopause Society recommended black cohosh for the treatment of women with menopausal symptoms [21]. A 20112012 randomized, double-blind, placebo-controlled clinical trial conducted on 84 early post-menopausal participants with Greene climacteric scale (GCS) scores of 15 to 42 showed that black cohosh extract reduced the total and subscale scores (vasomotor, psychiatric, physical, and sexual symptoms) during the 4-8 $\mathrm{w}$ of treatment [22-25]. Some studies found that chemicals in black cohosh extract do not bind to ERs in ligand binding assays with recombinant estrogen receptors [26]. However, we think that the estrogenic and antiestrogenic activities exhibited by S3 in the transgenic yeast system are induced by triterpene glycosides, especially cimicifugoside phytoestrogens specific to black cohosh $[27,28]$. It was suggested, based on preclinical findings that chemicals in black cohosh extracts with dopaminergic or serotoninergic activity rather than estrogenic activity ameliorate menopausal symptoms. Thus, black cohosh is considered a safe alternative to hormone replacement therapy even in patients with a history of hormone-responsive neoplasias since it induces apoptosis in human mammary tumor cells and does not have proliferative effects on crucial estrogen-responsive tissues [29-31].

The estrogenic and antiestrogenic activities of S3 and S4 are most likely due to the soy isoflavones in their formulations. S3 also contains plant materials known for their phytoestrogens, such as red clover and black cohosh, and S4 contains isoflavone glycosides besides a soy isoflavone concentrate of unknown composition (table 1). Red clover has been known to contain phytoestrogens, mostly isoflavones and some coumestans, which could act as either estrogen agonists or antagonists, depending on the phytoestrogen and its serum concentration [32]. The isoflavones formononetin, biochanin A, genistein and daidzein are present in red clover plants as glycosides and malonates [32]. The largest randomized study conducted by Tice et al. with 252 postmenopausal women reporting $\geq 35$ hot flashes per week to Promensil (red clover isoflavones; Novogen Ltd.), Rimostil (red clover isoflavones; Novogen Ltd.), or placebo for $12 \mathrm{w}$ showed no beneficial effects of red clover products over placebo in relieving hot flash [33]. Similarly, other studies reported by Barber et al. [34], and Knight et al. [35] showed no effects of red clover in alleviating the menopausal symptoms as compared to placebo. In contrast to the above studies, other studies reported a statistically significant reduction in hot flash frequency among women taking Promensil compared to placebo. Van de Weijer 
and Barentsen showed that consumption of Promensil $(80 \mathrm{mg} /$ day isoflavones) for $12 \mathrm{w}$ significantly reduced hot flashes in 30 randomized women reporting $\geq 5$ hot flashes per day [36]. Another 12-week randomized, controlled trial conducted on 72 postmenopausal women showed the effectiveness of dried leaves of red clover in reducing the severity of menopausal symptoms [37]. The systematic review and meta-analysis by Ghazanfarpour et al. [38] concluded that consumption of red clover is effective in decreasing hot flashes, especially in women with severe hot flashes ( $\geq 5$ per day).

S3 and S5 contain ingredients from several different plant species used in folk medicine to alleviate menopausal and other symptoms. Most of these ingredients possess estrogenic and/or antiestrogenic properties in different assay systems [39-46]. Although S5 is a pure herbal blend compared to S3, which contains mineral components and fish oil besides plant material, its extracts had the lowest estrogenic and antiestrogenic activities in the recombinant yeast system (table 2) indicating that some of the ingredients are very weak phytoestrogens and/or non-estrogenic ingredients interfered with the activity of phytoestrogens as reported before [47].

Except for S2 extract, all other non-digested dietary supplements showed higher estrogenic activities as methanol extracts than water extracts in the transgenic yeast system, whereas except for S2, S4 and S5 extracts (at 100E equivalents), all other supplement extracts displayed significantly higher antiestrogenic activities as methanol extracts than water extracts (table 2). It seems that methanol is a better solvent in extracting the active ingredients of the dietary supplements under study than water. In general, methanol is more efficient in the extraction of lower molecular weight phytochemicals such as flavonoids, proanthocyanidins, and tannins as compared to water [48]. Therefore, methanol formulations (tinctures) of dietary supplements may be more potent in delivering phytoestrogens for alleviating menopausal symptoms.

After GI digestion of dietary supplements, the 'IN SAMPLE' represents the serum-availability, and the 'OUT SAMPLE' represents the colonavailability of phytoestrogens. It is known that bioavailability and biological activities of supplement phytochemicals are affected by digestion and absorption in the blood stream. During the digestion process, bioactive compounds may undergo structural and chemical changes, which may result in variations in their biological activities [49]. Phytoestrogens exist in the form of inactive glycosides in plant tissues. A glycoside is a molecule containing a sugar bound to an aglycone, a non-sugar moiety and the active form of phytoestrogens. The isoflavone aglycones genistein and daidzein are present in soy primarily as the $p$-D glycosides genistin and daidzin, respectively [50]. The glycosidic forms of isoflavones are hydrolyzed by intestinal bacteria and enzymes and further metabolized through glucuronidation within the liver [50]. Daidzein is metabolized in the liver to equol or $o$-desmethylangolensin $(O-\mathrm{DMA})$ and genistein to pethyl phenol [51], three potent phytoestrogens derivatives that can be detected in human serum and urine [37]. In our study, S4 contains glycosidic forms of isoflavones, namely genistin, daidzin, and glycerin. The GI digestion of these glycosides resulted in aglycones that induced significantly higher estrogenic activities at $400 \mathrm{E}$ equivalents (760.8 $\pm 13 \mathrm{MU}$ as 'IN SAMPLE' and $1402.2 \pm 1 \mathrm{MU}$ as 'OUT SAMPLE', table 3) than the non-digested extract (443.9 $\pm 6.1 \mathrm{MU}$, table 2), which contains only phytoestrogen glycosides.

All digested supplement extracts induced increasing estrogenic and antiestrogenic activities with increasing concentrations. The S2 'IN SAMPLE' (400E equivalents) showed the highest estrogenic activity $(972.2 \pm 7.2 \mathrm{MU})$, whereas the highest antiestrogenic activity was displayed by S1 and S3 'IN SAMPLES' (400E equivalents) (table 3). S1 extract inhibited estradiol activity by 94\%, whereas S3 extract completely inhibited the estradiol activity (table 3). Similarly, S4 'OUT SAMPLE' (400E equivalents) showed the highest estrogenic activity $(1402.2 \pm 1 \mathrm{MU})$, whereas the highest antiestrogenic activity was detected in S5 'OUT SAMPLE' (table 3), which inhibited estradiol activity by $90 \%$. The estrogenic activities of the other 'IN SAMPLE' extracts of dietary supplements ranked as follows: S3 and S4>S1>S5, and for 'OUT SAMPLES' the ranking was: S5>S2 and S3>S1 (table 3). The antiestrogenic activities of other 'IN SAMPLE' extracts of dietary supplements ranked as follows: S4 and S5>S2 and for 'OUT SAMPLES' the ranking was: $\mathrm{S} 5>\mathrm{S} 3$ and $\mathrm{S} 4>\mathrm{S} 1>\mathrm{S} 2$ (table 3$)$. All extracts $(400 \mathrm{E}$ equivalents) showed significantly higher estrogenic activities as 'IN SAMPLES' compared to the corresponding 'OUT SAMPLES,' except for S4 and S5 extracts. The much higher estrogenic activity in S4 and S5 'OUT SAMPLES' than 'IN SAMPLES' could be explained by the fact that both gastric digests of these supplements had high concentrations of aglycones and a good portion of them did not diffuse in the dialysis tubing during the 2-h intestinal digestion phase. For the same reason, except for S1 and S3 extracts, the other extracts showed significantly higher antiestrogenic activities as 'OUT SAMPLES' than 'IN SAMPLES'.

Table 3: Estrogenic and antiestrogenic activities of simulated GI digestion extracts of dietary supplements

\begin{tabular}{|c|c|c|c|c|}
\hline \multicolumn{5}{|c|}{ Estrogenic activities (MU) } \\
\hline In samples & 100E Equiv & 200E Equiv & 300E Equiv & 400E Equiv \\
\hline S1 & $125.6 \pm 9.7$ & $333.3 \pm 3^{\text {(a) }}$ & $422.9 \pm 5^{\text {(a) }}$ & $610.8 \pm 28$ \\
\hline S2 & $403.3 \pm 15^{(*)}$ & $405.1 \pm 10.6$ & $437.8 \pm 25^{(\mathrm{ab})}$ & $972.2 \pm 7.2$ \\
\hline S3 & $470 \pm 23^{(*)}$ & $564 \pm 9^{(*)}$ & $620.8 \pm 4.3^{(\mathrm{a})\left({ }^{*}\right)}$ & $712.2 \pm 8.8^{(\mathrm{c})}$ \\
\hline S4 & $564.8 \pm 30.9$ & $\left.614.4 \pm 99^{*}\right)$ & $660.8 \pm 5.4$ & $760.8 \pm 13^{(c)}$ \\
\hline S5 & $239.7 \pm 13.8$ & $342.2 \pm 23^{(a)}$ & $362.2 \pm 25^{(a b)\left({ }^{*}\right)}$ & $466.2 \pm 19.2$ \\
\hline \multicolumn{5}{|l|}{ Out samples } \\
\hline S1 & $107.4 \pm 1.4$ & $130.7 \pm 4.1$ & $192.2 \pm 2$ & $215.6 \pm 5$ \\
\hline $\mathrm{S} 2$ & $169.3 \pm 2.3$ & $214.4 \pm 2.4$ & $365.6 \pm 10$ & $370 \pm 5^{(\mathrm{b})}$ \\
\hline S3 & $411.5 \pm 4.3$ & $444.1 \pm 2.1$ & $812.2 \pm 3(\mathrm{c})$ & $369.6 \pm 1^{(b)}$ \\
\hline S4 & $329.6 \pm 3.2$ & $414.1 \pm 3$ & $808.5 \pm 2^{\text {(c) }}$ & $1402.2 \pm 1$ \\
\hline S5 & $364.1 \pm 4$ & $542 \pm 1$ & $1092.2 \pm 2$ & $1242.6 \pm 3$ \\
\hline \multicolumn{5}{|c|}{ Antiestrogenic activities (\%) } \\
\hline In samples & 100E equiv & 200E equiv & $300 \mathrm{E}$ equiv & 400E equiv \\
\hline$\overline{\mathrm{S} 1}$ & $73.9 \pm 0.3$ & $76.5 \pm 1^{(\mathrm{a})\left(^{*}\right)}$ & $85.6 \pm 1$ & $93.9 \pm 0.3^{(\mathrm{a})}$ \\
\hline S2 & $20 \pm 0.4^{\text {(b) }}$ & $26.7 \pm 2^{(b)}$ & $26.9 \pm 0.7$ & $30.2 \pm 0.2$ \\
\hline S3 & $28.1 \pm 0.1^{(b c)}$ & $58.6 \pm 1^{(\mathrm{ac})}$ & $58.2 \pm 0.3^{(\mathrm{c})}$ & $100 \pm 0.1^{(\mathrm{a})}$ \\
\hline S4 & $21.5 \pm 0.5^{(\mathrm{bcd})}$ & $34.5 \pm 0.1^{(\mathrm{b})\left({ }^{*}\right)}$ & $69.3 \pm 7.2$ & $71.6 \pm 4.2^{(\mathrm{d})}$ \\
\hline S5 & $12.2 \pm 0.2^{(\mathrm{bcd})}$ & $51 \pm 0.6\left(\mathrm{c}\left({ }^{*}\right)\right.$ & $58.3 \pm 0.02^{(\mathrm{c})}$ & $63.3 \pm 0.2^{(\mathrm{d})}$ \\
\hline \multicolumn{5}{|l|}{ Out samples } \\
\hline S1 & $29.6 \pm 0.2$ & $51.2 \pm 0.1$ & $64.3 \pm 0.1$ & $72.2 \pm 0.2$ \\
\hline $\mathrm{S} 2$ & $32 \pm 1$ & $34.4 \pm 0.1$ & $50 \pm 0.03$ & $60.6 \pm 0.2$ \\
\hline S3 & $61.7 \pm 0.8$ & $69.6 \pm 0.4$ & $74.5 \pm 0.2$ & $80.3 \pm 0.1^{(\mathrm{c})}$ \\
\hline S4 & $26.6 \pm 0.1$ & $42.3 \pm 0.2$ & $60.4 \pm 0.2$ & $81 \pm 0.1^{(\mathrm{c})}$ \\
\hline S5 & $19.6 \pm 0.3$ & $38.9 \pm 0.1$ & $75.7 \pm 0.1$ & $90.2 \pm 0.5$ \\
\hline
\end{tabular}

Results represent means \pm SD of three independent experiments (each experiment had two replicates; $n=6$ ). In each column, mean values with no superscript letters are significantly different from each other at $\mathrm{R} 0.01$; mean values with * are significantly different fro $\mathrm{m}$ each other at $\mathrm{Z} \leq 0.05$; mean values with same superscript letters are not significantly different (Tukey's test). 
Although the simulated GI digestion of supplement extracts has its own limits, it showed that phytoestrogens in the supplement extracts were available for intestinal absorption and therefore validated the potency of the supplements under study. When the digested supplement extracts were compared to those of non-digested samples, S2, S4 and S5 'IN SAMPLES' showed higher estrogenic activities (972.2 $\pm 7.2 \mathrm{MU} ; 760.8 \pm 13$; and 466.2 \pm 4 , respectively) (table 3) compared to the corresponding non-digested water extracts (829.5 $\pm 20 \mathrm{MU}, 443.9 \pm 6.1 \mathrm{MU} ; 281.1 \pm 6.7 \mathrm{MU}$, respectively) (table 2). Similarly, all 'IN SAMPLES' except for S2 showed higher antiestrogenic activities (table 3 ) as compared to the corresponding non-digested extracts at $400 \mathrm{E}$ equivalents (table 2). Although the in vitro GI digestion does not completely illustrate the in vivo digestion process, it represents a simple, affordable, and reproducible method for evaluating the availability of bioactive in the bloodstream [52]. The increased estrogenic and antiestrogenic activities of digested supplement extracts in this study show that the GI digestion increased the availability of phytoestrogens in those extracts.

Chemicals with estrogenic activities found in or isolated from botanical supplements interact with estrogen receptors in human tissues inducing transactivation of certain genes [53]. The endogenous estrogen hormone, $17 \beta$-estradiol, is known to be involved in the development of mammary glands and uterus, maintenance of pregnancy and bone density, protection from cardiovascular diseases, and alleviation of menopausal symptoms [54-56]. The high estrogenic and antiestrogenic activities of the five dietary supplements as simulated GI digests in this study show that they may be beneficial in the treatment or prevention of the estrogen-deficient conditions such as menopausal symptoms, osteoporosis. Snelten et al. [57] reviewed the effects of popular botanical supplements on the key steps of estrogen metabolism and reported that botanical supplements containing black cohosh, dong gui, ginger, hops, licorice and red clover modulated key estrogen metabolizing enzymes such as aromatase, catechol- $O$-methyltransferase (COMT), NAD (P) H-quinone oxidoreductase 1 (NQO1), and reactive oxygen species (ROS) and therefore could protect against estrogen carcinogenesis. In our study, S1 and S3 extracts showed higher antiestrogenic activity in 'IN SAMPLES' and S2, S4 and S5 showed the highest antiestrogenic activity in 'OUT SAMPLES' (table 3), consistent with results of other studies on the antiestrogenic and anti-proliferative effects of plant ingredients and isoflavones in recombinant estrogen receptor assays and cancer cell cultures $[6,10-13,30,31,39,44,46,58-60]$.

\section{CONCLUSION}

The dietary supplements investigated in this study revealed estrogenic and antiestrogenic activities in the estrogen-responsive transcriptional system in yeast, confirming the presence of phytoestrogens in the supplement formulations. Moreover, the simulated GI digestion demonstrated the availability of phytoestrogens for absorption in the blood stream. Among the supplements studied, those containing soy isoflavones and alfalfa ingredients had the highest estrogenic activities and could be more effective than supplements with a complex plant formulation in alleviating menopausal symptoms and treating osteoporosis. More studies on a larger number of dietary supplements are necessary to determine if the antiestrogenic activities of candidate phytoestrogens in the supplements are effective in preventing and treating estrogen-induced cancers. The GI digestion coupled with the transgenic yeast assays proved to be a convenient and powerful tool for assessing the in vitro estrogenic and antiestrogenic activities of dietary supplements and could be easily adapted to routine quality control procedures for supplements aimed at treating menopausal symptoms.

\section{CONFLICT OF INTERESTS}

Authors have no conflict of interests

\section{REFERENCES}

1. Nelson LR, Bulun SE. Estrogen production and action. J Am Acad Dermatol 2001;45 Suppl 116-24.

2. Roush K. Managing menopausal symptoms. Am J Nurs 2012;112:28-35.
3. Rossouw JE, Anderson GL, Prentice RL, LaCroix AZ, Kooperberg C. Risks and benefits of estrogen plus progestin in healthy postmenopausal women: principal results from the women's health initiative randomized controlled trial. JAMA 2002; 288:321-33.

4. Geller SE, Studee L. Botanical and dietary supplements for menopausal symptoms: What works, what does not. J Womens Health 2005;14:634-49.

5. Pitkin J. Alternative and complementary therapies for the menopause. Menopause Int 2012;18:20-7.

6. Chrzan BG, Bradford PG. Phytoestrogens activate estrogen receptor beta1 and estrogenic responses in human breast and bone cancer cell lines. Mol Nutr Food Res Res 2007;51:171-7.

7. Dixon RA. Phytoestrogens. Annu Rev Plant Biol 2004;55:225-61.

8. Loewe S, Lange F, Spohr E. Über weibliche sexual hormone. Res Exp Med 1927;54:188-98.

9. Shah NR, Wong T. Current breast cancer risks of hormone replacement therapy in postmenopausal women. Expert Opin Pharmacother 2006; 7:2455-63.

10. Bak MJ, Das Gupta S, Wahler J, Suh N. Role of dietary bioactive natural products in estrogen receptor-positive breast cancer. Semin Cancer Biol 2016. http://dx.doi.org/10.1016/ j.semcancer.2016.03.001.

11. Boucher BA, Cotterchio M, Anderson LN, Kreiger N, Kirsh VA, Thompson LU. Use of isoflavone supplements is associated with reduced postmenopausal breast cancer risk. Int J Cancer 2013;132:1439-50.

12. Choi EJ, Kim GH. Antiproliferative activity of daidzein and genistein may be related to ERalpha/c-erbB-2 expression in human breast cancer cells. Mol Med Rep 2013;7:781-4.

13. Choi EJ, Jung JY, Kim GH. Genistein inhibits the proliferation and differentiation of MCF-7 and 3T3-L1 cells via the regulation of ER-alpha expression and induction of apoptosis. Exp Ther Med 2014;8:454-8.

14. McDougall GJ, Fyffe S, Dobson P, Stewart D. Anthocyanins from red wine their stability under simulated gastrointestinal digestion. Phytochemistry 2005;66:2540-8.

15. Maier CG, Chapman KD, Smith DW. Phytoestrogens and floral development in dioecious Maclura pomifera (Raf.)Schneid. and Morus rubra L. (Moraceae). Plant Sci 1997;130:27-40.

16. Seguin P, Zheng W, Souleimanov A. Alfalfa phytoestrogen content: impact of plant maturity and herbage components. J Agron Crop Sci 2004;190:211-7.

17. Hong $\mathrm{YH}$, Wang SC, Hsu C, Lin BF, Kuo YH, Huang CJ. Phytoestrogenic compounds in alfalfa sprout (Medicago sativa) beyond coumestrol. J Agric Food Chem 2011;59:131-7.

18. De Leo V, Lanzetta D, Cazzavacca R, Morgante G. Treatment of neurovegetative menopausal symptoms with a phytotherapeutic agent. Minerva Ginecol 1998;50:207-11.

19. Ma H, Sullivan-Halley J, Smith AW, Neuhouser ML, Alfano CM, Meeske K, et al. Estrogenic botanical supplements, healthrelated quality of life, fatigue, and hormone-related symptoms in breast cancer survivors: a HEAL study report. BMC Complementary Altern Med 2011;11:109.

20. World Health Organization. WHO Monographs on Selected Medicinal Plants. Volume 2. Geneva: World Health Organization; 2002. p. 55-65.

21. North American Menopause Society. Treatment of menopauseassociated vasomotor symptoms: a position statement of the North American Menopause Society. Menopause 2004;11:11-33.

22. Mohammad-Alizadeh-Charandabi S, Shahnazi M, Nahaee J, Bayatipayan S. Efficacy of black cohosh (Cimicifuga racemosa L.) in treating early symptoms of menopause: a randomized clinical trial. Chin Med 2013;8:20.

23. Blumenthal M, Busse WR, Goldberg A, Gruenwald J, Hall T, Riggins CW, et al. The complete german commission $\mathrm{e}$ monographs-therapeutic guide to herbal medicines. American Botanical Council, Austin, Texas. Integr Med Commun, Boston, MA 1998;36:138.

24. World Health Organization. WHO Monographs on Selected Medicinal Plants, Volume 1. Geneva: World Health Organization; 1999. p. 168.

25. Seo SK, Hong Y, Yun BH, Chon SJ, Jung YS, Park JH, et al. Antioxidative effects of Korean red ginseng in postmenopausal 
women: a double-blind, randomized controlled trial. J Ethnopharmacol 2014;154:753-7.

26. Wuttke W, Jarry H, Haunschild J, Stecher G, Schuh M, SeidlovaWuttke D. The non-estrogenic alternative for the treatment of climacteric complaints: black cohosh (Cimicifuga or Actaea racemosa). J Steroid Biochem Mol Biol 2014;139:302-10.

27. He K, Zheng B, Kim CH, Rogers L, Zheng Q. Direct analysis and identification of triterpene glycosides by LC/MS in black cohosh, Cimicifuga racemosa, and in several are commercially available black cohosh products. Planta Med 2000;66:635-40.

28. Woo KC, Park YS, Jun DJ, Lim JO, Baek WY, Suh BS, et al. Phytoestrogen cimicifugoside-mediated inhibition of catecholamine secretion by blocking nicotinic acetylcholine receptor in bovine adrenal chromaffin cells. J Pharmacol Exp Ther 2004;309:641-9.

29. Viereck V, Emons G, Wuttke W. Black cohosh: just another phytoestrogen? Trends Endocrinol Metab 2005;16:214-21.

30. Hostanska K, Nisslein T, Freudenstein J, Reichling J, Saller R. Cimicifuga racemosa extract inhibits proliferation of estrogen receptor-positive and negative human breast carcinoma cell lines by induction of apoptosis. Breast Cancer Res Treat 2004a;84:151-60.

31. Hostanska K, Nisslein T, Freudenstein J, Reichling J, Saller R. Evaluation of cell death caused by triterpene glycosides and phenolic substances from Cimicifuga racemosa extract in human MCF-7 breast cancer cells. Biol Pharm Bull 2004b;27:1970-5.

32. Beck V, Rohr U, Jungbauer A. Phytoestrogens derived from red clover: an alternative to estrogen replacement therapy? J Steroid Biochem Mol Biol 2005;94:499-518.

33. Tice JA, Ettinger B, Ensrud K, Wallace R, Blackwell T, Cummings SR. Phytoestrogen supplements for the treatment of hot flashes: The isoflavone clover extract (ICE) study: a randomized controlled trial. JAMA 2003;290:207-14.

34. Baber RJ, Templeman C, Morton T, Kelly GE, West L. Randomized placebo-controlled trial of an isoflavone supplement and menopausal symptoms in women. Climacteric 1999;2:85-92.

35. Knight DC, Howes JB, Eden JA. The effect of promensil, an isoflavone extract, on menopausal symptoms. Climacteric 1999;2:79-84

36. Van de Weijer PH, Barentsen R. Isoflavones from red clover (promensil) significantly reduce menopausal hot flush symptoms compared with placebo. Maturitas 2002;42:187-93.

37. Shakeri F, Taavoni S, Goushegir A, Haghani H. Effectiveness of red clover in alleviating menopausal symptoms: a 12-week randomized, controlled trial. Climacteric 2015;18:568-73.

38. Ghazanfarpour M, Sadeghi R, Roudsari RL, Khorsand I, Khadivzadeh T, Muoio B. Red clover for treatment of hot flashes and menopausal symptoms: A systematic review and meta-analysis. J Obstet Gynaecol 2016;36:301-11.

39. Poh SWM, Chia YY. Estrogenic and antiproliferative activity of water extract of Glycyrhizza uralensis (licorice root). Int J Phytomed 2013;5:119-24.

40. König S. Composition and activity of Vitex agnus Castus. Biomacromol Mass Spectrom 2014; 3:291-312.

41. Xu Y, Ding J, Ma XP, Ma YH, Liu ZQ, Lin N. Treatment with Panax ginseng antagonizes the estrogen decline in ovariectomized mice. Int J Mol Sci 2014;15:7827-40.

42. Deka A, Kalita JC, Singh YR, Deka M. Determination of estrogenicity of Asoca plant (Saraca asoca Linn.) in adult female ovariectomized mice. Int J Recent Sci Res 2012;6:7661-4.

43. Kamat SK, Barde PJ, Raut SB. Evaluation of the estrogenic activity of Indian medicinal plants in immature rats. Ancient Sci Life 2015;35:90-5.

44. Singla R, Jaitak V. Molecular docking simulation study of phytoestrogens from Asparagus racemosus in breast cancer progression. Int J Pharm Sci Res 2015;6:172-82.
45. Wang T, Wan D, Shao L, Dai J, Jiang C. Notoginsenoside R1 stimulates osteogenic function in primary osteoblasts via estrogen receptor signaling. Biochem Biophys Res Commun 2015;466:232-9.

46. Muhit MA, Umehara K, Mori-Yasumoto K, Noguchi H. Furofuran lignin glucosides with estrogen-inhibitory properties from the Bangladeshi medicinal plant Terminalia citrina. J Nat Prod 2016;79:1298-307.

47. Polasek J, Hostettmann K. The importance of phytoestrogens in food supplements and phytopharmaceuticals. Chimia 2005;59:331-5.

48. Dai J, Mumper RJ. Plant phenolics: extraction, analysis and their antioxidant and anticancer properties. Molecules 2010;15:7313-52.

49. Celep E, Charehsaz M, Akyüz S, Acar ET, Yesilada E. Effect of in vitro gastrointestinal digestion on the bioavailability of phenolic components and the antioxidant potentials of some Turkish fruit wines. Food Res Int 2015;78:209-15.

50. Setchell KD, Brown NM, Desai P, Zimmer-Nechemias L, Wolfe $\mathrm{BE}, \mathrm{Brashear} \mathrm{WT}$, et al. Bioavailability of pure isoflavones in healthy humans and analysis of commercial soy isoflavone supplements. J Nutr 2001;131 Suppl:1362-75.

51. Setchell KD. Phytoestrogens: the biochemistry, physiology, and implications for human health of soy isoflavones. Am J Clin Nutr 1998;68 Suppl:1333-46.

52. Alminger M, Aura AM, Bohn T, Dufour C, El SN, Gomes A, et al. In vitro models for studying secondary plant metabolite digestion and bioaccessibility. Compr Rev Food Sci Food Saf 2014;13:413-36.

53. Jiang Y, Gong P, Madak-Erdogan Z, Martin T, Jeyakumar M, Carlson $\mathrm{K}$, et al. Mechanisms enforcing the estrogen receptor $\beta$ selectivity of botanical estrogens. FASEB 2013;27:4406-18.

54. Ames MS, Hong S, Lee HR, Fields HW, Johnston WM, Kim DG. Estrogen deficiency increases the variability of tissue mineral density of alveolar bone surrounding teeth. Arch Oral Biol 2010;55:599-605.

55. Pastore MB, Jobe SO, Ramadoss J, Magness RR. Estrogen receptor-alpha and estrogen receptor-beta in the uterine vascular endothelium during pregnancy: functional implications for regulating uterine blood flow. Semin Reprod Med 2012;30:46-61.

56. Nofer JR. Estrogens and atherosclerosis: insights from animal models and cell systems. J Mol Endocrinol 2012;48:R13-R29.

57. Snelten CS, Dietz B, Bolton JL. Modulation of estrogen chemical carcinogenesis by botanical supplements used for postmenopausal women's health. Drug Discovery Today: Dis Mech 2012;9:47-54.

58. Hostanska K, Nisslein T, Freudenstein J, Reichling J, Saller R. Inhibitory effect of an isopropanolic extract of black cohosh on the invasiveness of MDA-MB 231 human breast cancer cells. In Vivo 2007;21:349-55.

59. Andres S, Hansen U, Niemann B, Palavinskas R, Lampen A. Determination of the isoflavone composition and estrogenic activity of commercial dietary supplements based on soy or red clover. Food Funct 2015;6:2017-25.

60. Coldham NG, Sauer MJ. Identification, quantitation and biological activity of phytoestrogens in a dietary supplement for breast enhancement. Food Chem Toxicol 2001;39:1211-24.

\section{How to cite this article}

- Paramita Basu, Sharon Sunny, Camelia Maier. Estrogenic and antiestrogenic activities of commercial dietary supplements containing herbal ingredients and isoflavones. Int J Pharm Pharm Sci 2016;8(11):307-312. 